\title{
Microstrip patch antenna with metamaterial using superstrate technique for wireless communication
}

\author{
Rasha Mahdi Salih, Ali Khalid Jassim \\ Electrical Engineering Department, College of Engineering, Mustansiriyah University, Baghdad, Iraq
}

\begin{tabular}{|c|c|}
\hline Article Info & ABSTRACT \\
\hline Article history: & This work builds a metamaterial (MTM) superstrate loaded on a patch of \\
\hline Received Sep 11, 2020 & $\begin{array}{l}\text { microstrip antenna for wireless communications. The MTM superstrate is } \\
\text { made up of four G-shaped resonators on FR-4 substrate with a relative }\end{array}$ \\
\hline Revised Apr 29, 2021 & permittivity of 4.4 and has a total area of $(8 \times 16) \mathrm{mm}^{2}$, and is higher than the \\
\hline Accepted May 25, 2021 & $\begin{array}{l}\text { patch. The MTM superstrate increases antenna gain while also raising the } \\
\text { input reflection coefficient. When it is } 9 \mathrm{~mm} \text { above the patch, the gain }\end{array}$ \\
\hline Keywords: & $\begin{array}{l}\text { increased from } 3.28 \mathrm{~dB} \text { to } 6.02 \mathrm{~dB} \text {, and when it is } 7 \mathrm{~mm} \text { above the patch, the } \\
\text { input reflection coefficient was enhanced from }-31.217 \mathrm{~dB} \text { to }-45.8 \mathrm{~dB} \text {. When }\end{array}$ \\
\hline $\begin{array}{l}\text { Input reflection coefficient } \\
\text { Metamaterial }\end{array}$ & $\begin{array}{l}\text { the MTM superstrate loaded antenna was compared to the traditional } \\
\text { unloaded antenna, it was discovered that metamaterials have a lot of potential } \\
\text { for improving antenna performance. }\end{array}$ \\
\hline
\end{tabular}

This is an open access article under the CC BY-SA license.

Superstrate

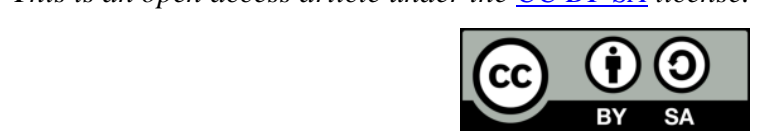

\section{Corresponding Author:}

Rasha Mahdi Salih

Department of Electrical Engineering

Mustansiriyah University

Baghdad, Iraq

Email: Asdfx7871@gmail.com

\section{INTRODUCTION}

The special properties of metamaterials have enticed scientists to develop highly efficient antennas for future wireless communication [1]. No other ordinary/naturally occurring metamaterial has the property that a metamaterial does [2]-[6]. Metamaterials are man-made structures that are engineered to have properties that aren't found in nature. Veselago introduced the first metamaterial definition [7]-[9]. Metamaterials are made up of unit cells that are organized in a regular pattern [10]-[15]. Tiny metallic resonators with a duration much shorter than the wavelength make up the unit cells. Different shapes are possible for the unit cell. Metamaterial structures may be used to miniaturize a large antenna, add a second resonance to a multiband antenna, increase the gain of a conventional antenna, increase the bandwidth of a narrow band antenna, and add a second resonance to a multiband antenna [16]-[25]. The metamaterial's exotic properties can be removed to achieve all of the antenna's aforementioned properties. In this study, we propose a metamaterials unit cell to obtain resonances at $6 \mathrm{GHz}$. The unit cell is a G-shaped split ring resonator (GSRR). The dielectric constant of the usable FR4 substrate is 4.4 and the height is $1.6 \mathrm{~mm}$.

\section{DESIGN OF THE METASURFACE UNIT CELL}

The proposed metamaterial unit cell is made up of four symmetrically aligned GSRR. Placing the cell in the middle determines the medium parameters. In Figure 1, the proposed GSRR's extensive dimension layout and the electrical circuit represented it is. Table 1 shows the dimensions of the proposed metasurface unit cell. The input reflection cofficient (S11) of the metasurface unit cell as shown in Figure 2. 


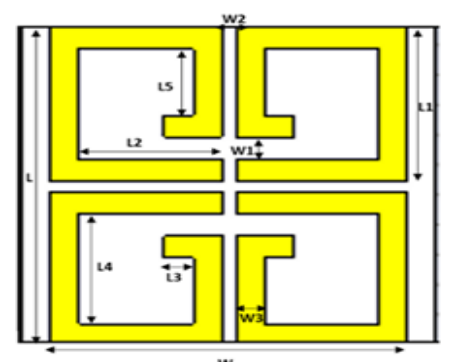

(a)

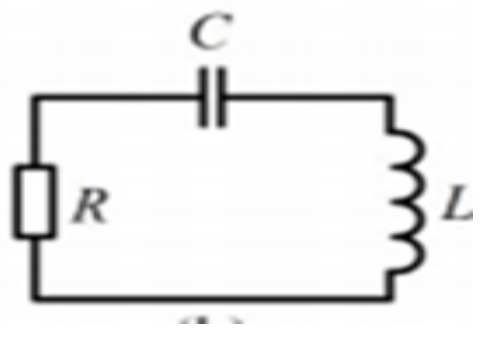

(b)

Figure 1. These figures are; (a) front view for the unit cell, (b) the unit cell's equivalent circuit

Table 1. Dimensions of metasurface unit cell

\begin{tabular}{ccccc}
$\mathrm{W} 1=0.55$ & $\mathrm{~W} 2=0.28$ & $\mathrm{~W} 3=0.55$ & $\mathrm{~L}=8$ & $\mathrm{~W}=8$ \\
\hline $\mathrm{L} 1=3.86$ & $\mathrm{~L} 2=2.76$ & $\mathrm{~L} 3=0.55$ & $\mathrm{~L} 4=2.76$ & $\mathrm{~L} 5=1.65$ \\
\hline
\end{tabular}

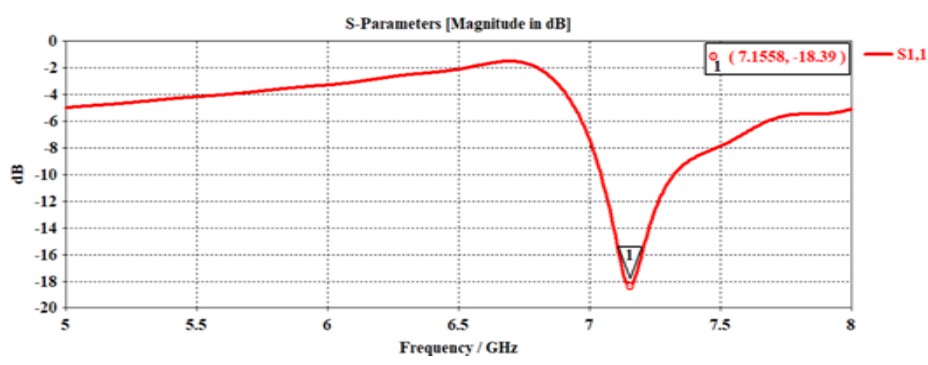

Figure 2. (S11) of the metasurface unit cell

\section{DESIGN OF PROPOSED MICROSTRIP ANTENNA}

The proposed antenna consists of a ground plane and a $1.6 \mathrm{~mm}$ thick FR4 dielectric substrate, and a relative permittivity of 4.4 . The microstrip antenna operates at $7.26 \mathrm{GHz}$, the microstrip patch antenna was developed. Table 2 and Table 3 display the design parameters for the microstrip antenna as shown in Figure 3.

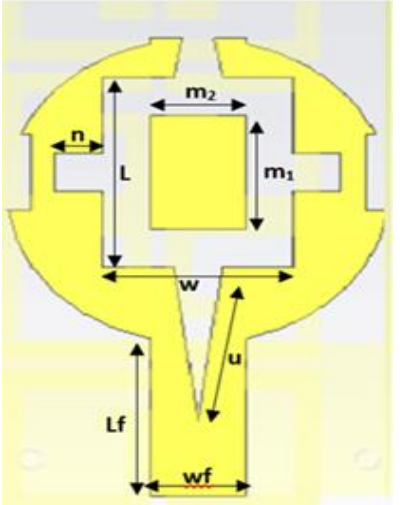

(a)

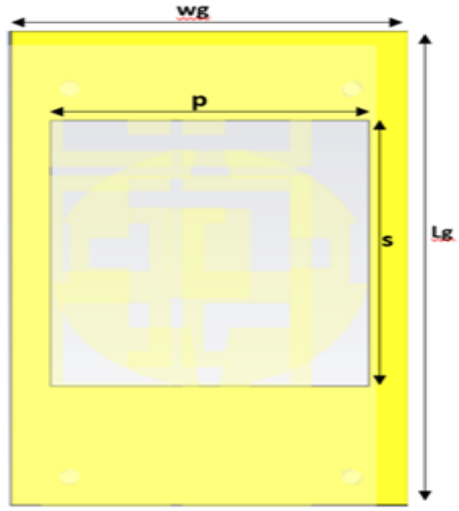

(b)

Figure 3. These figures are; (a) the patch for proposed microstrip antenna, (b) the ground plane for proposed microstrip antenna 
Table 2. Dimensions for the proposed microstrip antenna

\begin{tabular}{cc}
\hline Symbol & Value $(\mathrm{mm})$ \\
\hline $\mathrm{m}_{1}$ & 3 \\
$\mathrm{~m}_{2}$ & 2 \\
$\mathrm{~L}$ & 5 \\
$\mathrm{~N}$ & 1 \\
$\mathrm{~W}$ & 4 \\
$\mathrm{U}$ & 4.03 \\
$\mathrm{~S}$ & 9 \\
$\mathrm{P}$ & 8 \\
\hline
\end{tabular}

Table 3. Dimensions for the proposed microstrip antenna

\begin{tabular}{ccc}
\hline Parameter & Quality & value $(\mathrm{mm})$ \\
\hline $\mathrm{Lg}$ & Length of ground & 16 \\
$\mathrm{Wg}$ & Width of ground & 10 \\
$\mathrm{Ht}$ & thickness of the copper & 0.035 \\
$\mathrm{Ls}$ & Length of substrate & 16 \\
$\mathrm{Hs}$ & Height of substrate & 1.6 \\
$\mathrm{Ws}$ & Width of substrate & 10 \\
$\mathrm{Lf}$ & Length of the feed line & 4.13 \\
$\mathrm{Wf}$ & Width of the feed line & 2 \\
\hline
\end{tabular}

The microstrip antenna's input reflection coefficient was calculated at $7.26 \mathrm{GHz}$, and it was discovered that the proposed antenna had an input reflection coefficient of $-31.217 \mathrm{~dB}$, as shown in Figure 4. The gain of the microstrip patch antenna at $7.26 \mathrm{GHz}$ is $3.28 \mathrm{~dB}$ as shown in Figure 5.

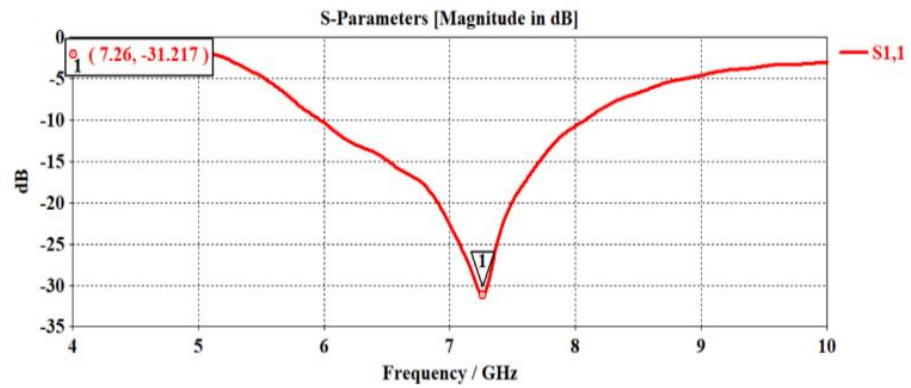

Figure 4. Input reflection coefficient for proposed antenna

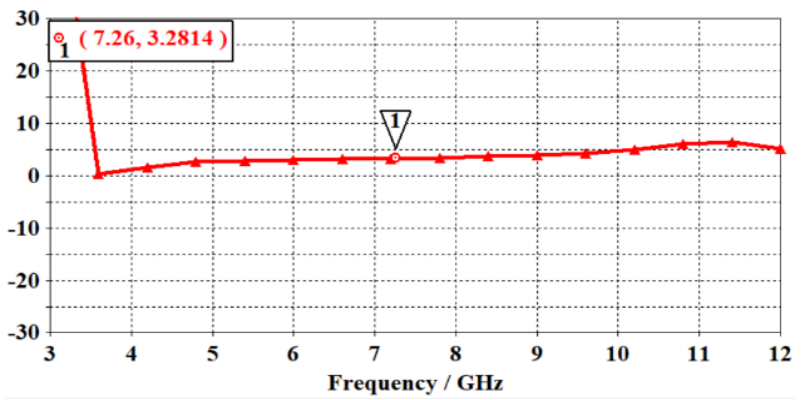

Figure 5. The gain for microstrip proposed antenna

\section{METAMATERIAL SUPERSTRATE ANALYSIS}

The geometrical structure of a metamaterial superstrate made up of a $(2 \times 1)$ cell array of the GSRR unit cell is shown in Figure 6 (a), Figure 6 (b), and Figure 6 (c) show viewpoint and side views of the proposed antenna. The MTM superstrate is used to cover the typical antenna's patch without increasing the total antenna area, i.e. the planer areas. The CST microwave studio package, which is based on the finite integration technique, was used to analyze the proposed antenna. 


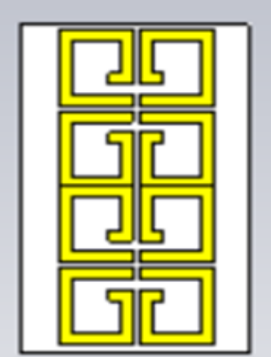

(a)

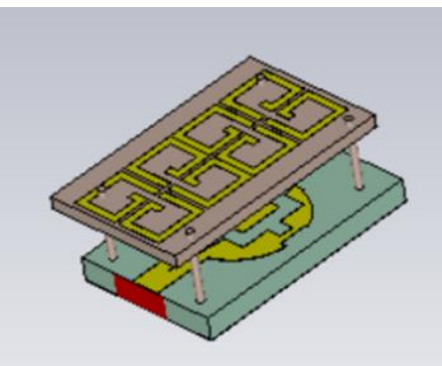

(b)

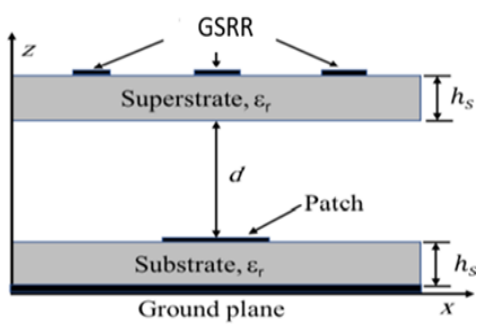

(c)

Figure 6. These figures are, (a) MTM superstrate geometrical structure, (b) side view, (c) perspective view

\section{PARAMETRIC STUDY}

CST's parameter sweep option was used to carry out the parametric studies to obtain maximum enhancement in gain and the input reflection coefficient of the proposed antenna. Figure 7 and Figure 8 illustrate the variation of the gain and the input reflection coefficient, respectively, at $7.26 \mathrm{GHz}$ of the proposed antenna with the amendment in the separation $d$ (where $d$ is the distance between the patch and the metamaterial superstrate). Maximum gain is obtained for $\mathrm{d}=9 \mathrm{~mm}$ and the maximum $\mathrm{S} 11$ is obtained at the distance $\mathrm{d}=7 \mathrm{~mm}$.

To obtain the optimum gain enhancement of the proposed antenna, parametric studies were carried out using the parameter sweep option in CST. Figure 7 and Figure 8 show the difference in gain and S11, respectively, of the designed antenna at $7.26 \mathrm{GHz}$ after the distance was modified. At a distance of $9 \mathrm{~mm}$, the maximum gain is obtained, and the maximum $\mathrm{S} 11$ is obtained for $\mathrm{d}=7 \mathrm{~mm}$.

The cavity effect can be used to describe the proposed antenna gain increase. Arises when the GSRR MTM superstrate is raised above the patch at a suitable distance. According to snell's law of refraction, a medium with a low refractive index scatters electromagnetic waves away from the main source and in the direction of the medium's normal. The surface this function increases the proposed antenna's directivity significantly. The MTM superstrate acts as a highly reflective surface, making the antenna extremely effective. The existence of MTM superstrate also affects the antenna's field distribution. The proposed antenna's overall gain would be improved by making it more homogeneous.

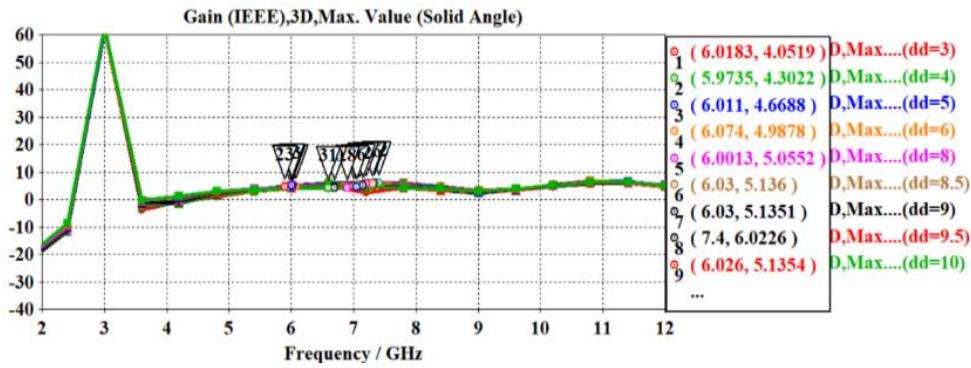

Figure 7. Gain parametric analysis for various distances

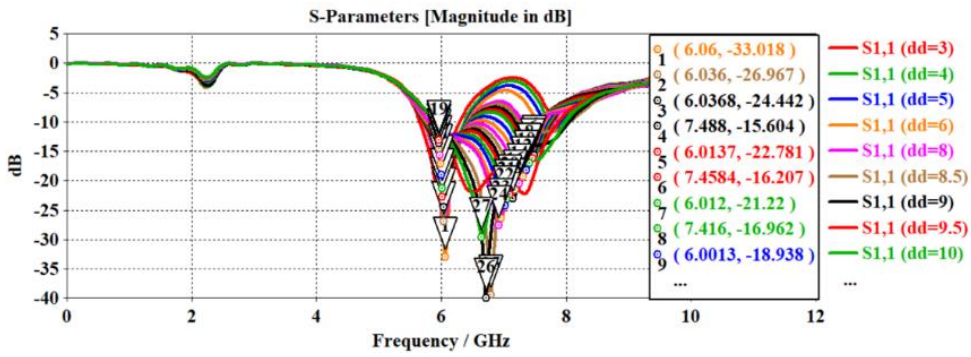

Figure 8. S11 parametric analysis for different distances 
After reviewing the parametric study results, the distance to achieve the best result for $\mathrm{S} 11 \mathrm{is} \mathrm{d}=7$ as shown in Figure 9. Figure 10 shows the frequencies that will be used if we set a distance of $9 \mathrm{~mm}$. At d=9, the maximum gain is reached, as illustrated in Figure 11.

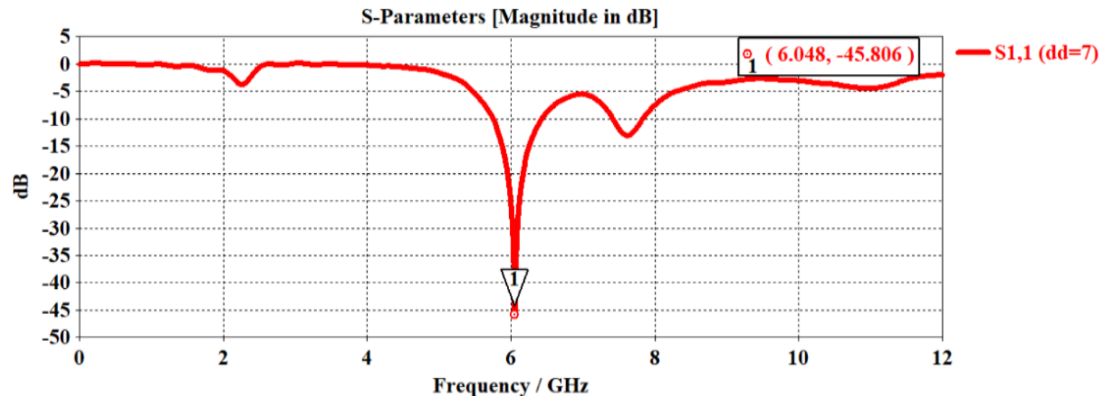

Figure 9. The input reflection coefficient at the distance $7 \mathrm{~mm}$

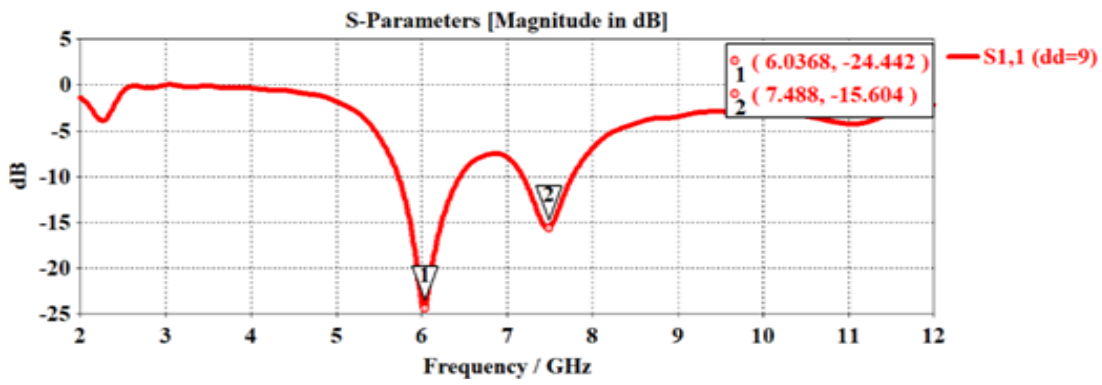

Figure 10. Input reflection coefficient at the distance $9 \mathrm{~mm}$

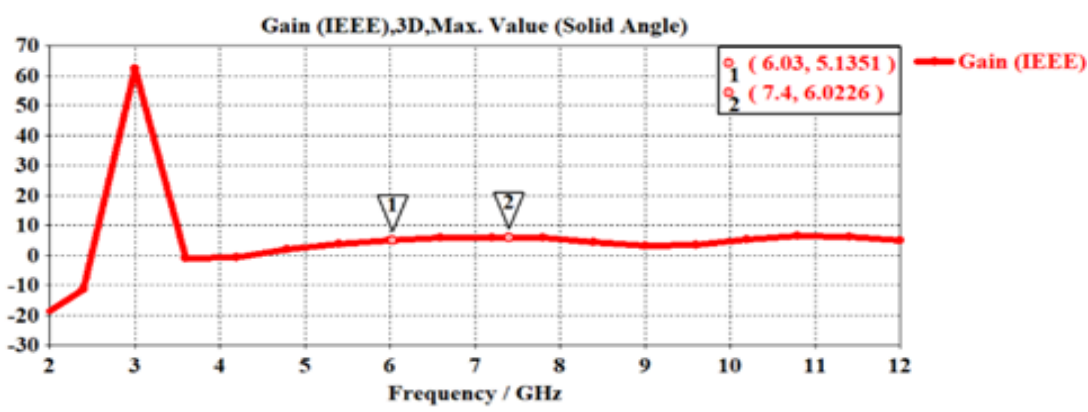

Figure 11. The gain at the distance $9 \mathrm{~mm}$

\section{CONCLUSION}

For wireless communications, an MTM superstrate loaded on the patch of microstrip antenna is built in this paper. The MTM superstrate has a total area of $(8 \times 16) \mathrm{mm}^{2}$ and is made up of four G-shaped resonators put on a substrate that is made of FR-4 with a relative permittivity of 4.4. The MTM superstrate is higher than the patch. That increases the antenna gain while also raising the input reflection coefficient when it is located at $9 \mathrm{~mm}$ and $7 \mathrm{~mm}$ above the patch. When the MTM superstrate-loaded antenna was compared to the traditional unloaded power, it was discovered that metamaterials have a lot of potential for improving antenna performance.

\section{ACKNOWLEDGEMENTS}

The authors would like to express their gratitude to Mustansiriyah University (www.uomustansiriyha.edu.iq) in Baghdad, Iraq, for their assistance with this work. 


\section{REFERENCES}

[1] T. Ali, S. Pathan, and R. Biradar, "Frequency Reconfigurable and Metamaterial Antennas Design TechniquesPresent and Future Research Directions," Internet Technology Letters, vol. 1, no. 10, p. e19, 2018, doi: 10.1002/it12019.

[2] V. G. Veselago, "The electrodynamics of substances with simultaneously negative values of and $\mu$," Soviet physics uspekhi, vol. 10, no. 4, pp. 509-514, 1968

[3] M. Lapine and S. Tretyakov," Contemporary notes on metamaterials," IET microwaves, antennas \& propagation, vol. 1, no. 1, pp. 3-11, 2007, doi: 10.1049/iet-map:20050307.

[4] T. Ali, M. Khaleeq, S. Pathan, and R. Biradar, "A multiband antenna loaded with metamaterial and slots for GPS/WLAN/WiMAX applications," Microwave and Optical Technology Letters, vol. 60, no. 1, pp. 79-85, 2018, doi: 10.1002/mop.30921.

[5] Tanweer Ali and Rajashekhar C. Biradar, "A Miniaturized Volkswagen Logo UWB Antenna with Slotted Ground Structure and Metamaterial for GPS," Progress in Electromagnetics Research C, vol. 72, pp. 29-41, 2017, doi: 10.2528/PIERC16120109.

[6] Y. Dong and T. Itoh, "Metamaterial-Based Antennas," in Proceedings of the IEEE, vol. 100, no. 7, pp. 2271-2285, July 2012, doi: 10.1109/JPROC.2012.2187631.

[7] Y. Dong, H. Toyao and T. Itoh, "Design and Characterization of Miniaturized Patch Antennas Loaded With Complementary Split-Ring Resonators," in IEEE Transactions on Antennas and Propagation, vol. 60, no. 2, pp. 772-785, Feb. 2012, doi: 10.1109/TAP.2011.2173120.

[8] F. Raval, Y. P. Kosta, and H. Joshi, "Reduced size patch antenna using complementary split ring resonator as defected ground plane," AEU-International Journal of Electronics and Communications, vol. 69, no. 8, pp. 11261133, 2015, doi: 10.1016/j.aeue.2015.04.013.

[9] Yang Cao, Xing Yu, Hongquan Feng, Rubing Han and Yuanyun Liu, "Waveguide demonstration of active frequency selective surface in K-band," 2016 Progress in Electromagnetic Research Symposium (PIERS), 2016, pp. 3735-3739, doi: 10.1109/PIERS.2016.7735414.

[10] D. R. Smith, D. C. Vier, Th. Koschny, and C. M. Soukoulis, "Electromagnetic parameter retrieval from inhomogeneous metamaterials," Physical review E, vol. 71, no. 3, p. 036617, 2005.

[11] Z. Szabó, G. Park, R. Hedge and E. Li, "A Unique Extraction of Metamaterial Parameters Based on KramersKronig Relationship," in IEEE Transactions on Microwave Theory and Techniques, vol. 58, no. 10, pp. 2646-2653, Oct. 2010, doi: 10.1109/TMTT.2010.2065310.

[12] A. A. Jabber, A. K. Jassim, and R. H. Thaher, "Compact reconfigurable PIFA antenna for wireless applications," Telkomnika, vol. 18, no. 2, pp. 595-602, 2020, doi: 10.12928/telkomnika.v18i2.13427.

[13] Z. Szabó, G. Park, R. Hedge and E. Li, "A Unique Extraction of Metamaterial Parameters Based on KramersKronig Relationship," in IEEE Transactions on Microwave Theory and Techniques, vol. 58, no. 10, pp. 2646-2653, Oct. 2010, doi: 10.1109/TMTT.2010.2065310.

[14] A. Benedetti, C. Sibilia, and M. Bertolotti, "Wideband negative magnetic permeability materials (NMPM) with composite metal-semiconductor structures based on the Drude model, and applications to negative-refractive index (NIM)," Optics Express, vol. 15, no. 11, pp. 6534-6545, 2007, doi: 10.1364/OE.15.006534.

[15] J. B. Pendry, A. J. Holden, D. J. Robbins, and W. J. Stewart, "Low-frequency plasmons in thin-wire structures," Journal of Physics: Condensed Matter, vol. 10, no. 22, p. 4785, 1998, doi: 10.1088/0953-8984/10/22/007.

[16] J. B. Pendry, A. J. Holden, W. J. Stewart, and I. Youngs, "Extremely low-frequency plasmons in metallic mesostructures," Physical review letters, vol. 76, no. 25, p. 4773, 1996, doi: 10.1103/PhysRevLett.76.4773.

[17] A. Alu and N. Engheta, "Pairing an epsilon-negative slab with a mu-negative slab: resonance, tunneling and transparency," in IEEE Transactions on Antennas and Propagation, vol. 51, no. 10, pp. 2558-2571, Oct. 2003, doi: 10.1109/TAP.2003.817553.

[18] D. R. Smith, D. C. Vier, T. Koschny, and C. M. Soukoulis, "Electromagnetic parameter retrieval from inhomogeneous metamaterials," Physical review $E$, vol. 71, no. 3, p. 36617, 2005, doi: 10.1103/PhysRevE.71.036617.

[19] A. K. Jassim, M. Jasim, A. F. Fahad, "Design selective band antenna using coupling sidewall and multi resonator for wireless communications," Bulletin of Electrical Engineering and Informatics, vol. 9, no. 5, pp. 2206-2212, 2020, doi: 10.11591/eei.v9i5.2247.

[20] J. Baker-Jarvis, E. J. Vanzura and W. A. Kissick, "Improved technique for determining complex permittivity with the transmission/reflection method," in IEEE Transactions on Microwave Theory and Techniques, vol. 38, no. 8, pp. 1096-1103, Aug. 1990, doi: 10.1109/22.57336.

[21] X. Chen, T. M. Grzegorczyk, B.-I. Wu, J. Pacheco Jr, and J. A. Kong, "Robust method to retrieve the constitutive effective parameters of metamaterials," Physical review E, vol. 70, no. 1, p. 16608, 2004, doi: 10.1103/PHYSREVE.70.016608.

[22] H. A. Majid, M. K. A. Rahim and T. Masri, "Left handed metamaterial design for microstrip antenna application," 2008 IEEE International RF and Microwave Conference, 2008, pp. 218-221, doi: 10.1109/RFM.2008.4897426.

[23] G. Kiziltas and J. L. Volakis, "Miniature antenna designs on metamaterial substrates," in 3rd European Workshop on Conformal Antennas, (Invited Paper), Bonn, Germany, 2003.

[24] Y. Dong and T. Itoh, "Metamaterial-Based Antennas," in Proceedings of the IEEE, vol. 100, no. 7, pp. 2271-2285, July 2012, doi: 10.1109/JPROC.2012.2187631. 
[25] Ali Khalid Jassim and R. H. Thaher, "Design and analysis microstrip antenna with a reflector to enhancement gain for wireless communication," Bulletin of Electrical Engineering and Informatics, vol. 9, no. 2, pp. 652-660, 2020, doi: 10.11591/eei.v9i2.1696.

[26] K. Aydin and E. Ozbay, "Left-handed metamaterial-based superlens for subwavelength imaging of electromagnetic waves," Applied Physics A, vol. 87, no. 2, pp. 137-141, 2007, doi: 10.1007/s00339-006-3817-4.

\section{BIOGRAPHIES OF AUTHORS}

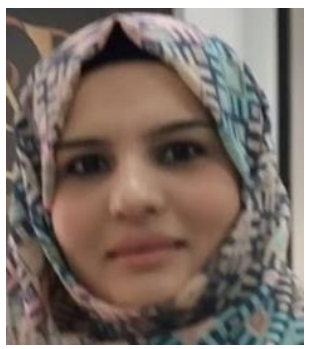

Rasha Mahdi Salih: received the B.S. E. E. degrees in electrical engineering from Mustansiriyh University, Baghdad, Iraq, in 2008. Her current research interest, in the areas of microstrip antennas with metasurface for a master's degree. E-mail: asdfx7871@gmail.com

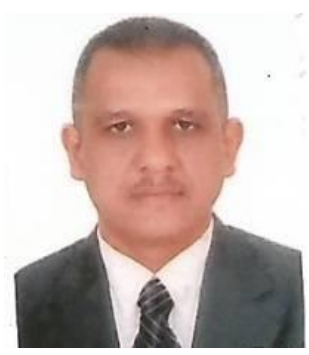

Asst. Prof. Dr. Ali Khalid Jassim: at Mustansiriyah University, college Engineering of Electrical Engineering Department. Holds a Bachelor's degree in 1999 and a Master's degree in 2010 and a Ph.D. in 2019 in communications engineering. Works in the field of cellular networks communications and antennas and has a many of research in international journals and scientific conferences. E-mail: alijassim79@yahoo.com, alijassim@uomustansiriyah.edu.iq 